\title{
Predictive service life analysis of characteristic applications of zeolite concrete in building structures
}

\author{
V. Kočí, M. Jerman, J. Maděra \& R. Černý \\ Department of Materials Engineering and Chemistry, \\ Faculty of Civil Engineering, Czech Technical University in Prague, \\ Czech Republic
}

\begin{abstract}
Service life prediction analysis of a building envelope made of concrete containing natural zeolite as supplementary cementitious material is presented in the paper. Coupled heat and moisture transport, which can cause the appearance of freeze/thaw cycles leading to subsequent mechanical damage, is assumed as the main damage mechanism. Moisture and temperature fields are predicted using numerical analysis based on the finite element method. As boundary conditions, the dynamic climatic data for Prague are utilized. Four different types of zeolite concrete are applied as the load bearing structure. The analyzed building envelope is assumed either without any surface layers or provided with external and internal plasters. The most complex case is the envelope with expanded polystyrene as a thermal insulation layer and plasters on both surfaces. Computational results indicate that the amount of zeolite in the concrete mix should be chosen with care, taking into account the specific conditions of concrete application.

Keywords: natural zeolite, concrete, finite element method, heat and moisture transport, climatic data, numerical analysis.
\end{abstract}

\section{Introduction}

In today's concrete industry, supplementary cementitious materials (SCM) became quite common $[1,2]$, because they can lead to clear and immediate environmental benefits and can reduce the energy consumption and greenhouse gases emission related to the cement production [3]. SCM are usually 
represented by industrial waste products such as fly ashes, silica fume or metallurgical slag, and agricultural waste products such as rice husk ash, wheat straw ash, or sugarcane bagasse ash [4]. Providing comparable performance, SCM are mostly cheaper than Portland cement, therefore they bring also economical benefits. From the technological point of view the utilization of some waste materials in the form of SCM may provide solutions for durability requirements which cannot be readily met with normal Portland cement.

As supplementary binders, natural materials were used since ancient times, due to their pozzolanic properties. At present, natural pozzolans are used as SCM for Portland cement concrete mainly in the countries where they are easily available. Natural zeolites are probably the most often used natural SCM. For instance, China or Iran, having vast resources of natural zeolites, report their wide applications in concrete industry. However, despite the positive effects of pozzolanic properties of natural zeolites on concrete properties, their application in comparison with, for instance, silica fume, metakaolin, fly ash or ground granulated blast furnace slag as SCM was much lower, until now.

Because zeolite concrete is relatively new building material, its performance, standing alone or in combination with other building materials, can be hardly predicted. The optimality of composition of zeolite concrete building envelopes can be judged from many points of view, e.g., service life, mechanical properties, or salt resistance. In this paper, we investigate the service life of zeolite concrete building envelopes with different types of thermal insulation or external finishes using computational analysis on the finite element basis.

\section{Composition of zeolite concretes}

The composition of zeolite concrete mixtures applied in [5] was assumed in the calculations throughout this paper (see Table 1).

Table 1: Composition of zeolite concrete mixtures.

\begin{tabular}{|l|c|c|c|c|}
\hline \multirow{2}{*}{ Component } & \multicolumn{4}{|c|}{ Composition $\left[\mathrm{kg} / \mathrm{m}^{3}\right]$} \\
\cline { 2 - 5 } & ZC-ref & ZC-10 & ZC-20 & ZC-40 \\
\hline CEM I 42.5 R & 484 & 436 & 387 & 305 \\
\hline Zeolite & - & $48(10 \%)$ & $97(20 \%)$ & $179(40 \%)$ \\
\hline Aggregates 0-4 mm & 812 & 812 & 812 & 812 \\
\hline Aggregates 8-16 mm & 910 & 910 & 910 & 910 \\
\hline $\begin{array}{l}\text { Plasticizer Mapei } \\
\text { Dynamon SX }\end{array}$ & 5.3 & 5.3 & 5.3 & 5.3 \\
\hline Water & 172 & 194 & 221 & 244 \\
\hline
\end{tabular}

The concrete mixtures were prepared using Portland cement CEM I 42.5 R as the main binder. A part of cement was replaced by natural zeolites (10-40\%). Chemical composition of cement and zeolite is summarized in Table 2. 
Table 2: Chemical composition of cement and zeolite.

\begin{tabular}{|c|c|c|c|c|c|c|c|c|c|c|c|}
\hline \multicolumn{2}{|l|}{ Component } & 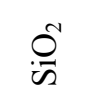 & 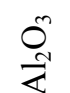 & $\underbrace{m}_{\mathbb{N}}$ & ర్ల & $\sum_{\sum}^{0}$ & $\begin{array}{l}\underset{\sim}{0} \\
\underline{1}\end{array}$ & $\begin{array}{l}\text { O } \\
\text { Z }\end{array}$ & $\overbrace{0}^{N}$ & $0^{n}$ & O̊ \\
\hline \multirow{2}{*}{$\begin{array}{l}\text { Amount } \\
{[\% \text { by mass }]}\end{array}$} & Cement & 21.89 & 5.6 & 3.75 & 62.33 & 1.4 & 0.92 & 0.11 & 0.3 & 0.17 & 2.88 \\
\hline & Zeolite & 68.15 & 12.3 & 1.3 & 2.63 & 0.9 & 2.8 & 0.75 & 0.2 & - & - \\
\hline
\end{tabular}

\section{Computational analysis}

The computational analysis was performed using the computer code HEMOT [6], which is based on the general finite element package SIFEL [7]. The basic parameters of the analysis, i.e., the mathematical model, hygric, thermal and basic physical properties of used materials, the scheme of the construction detail, initial and boundary conditions and the time specification of the simulation are described in what follows.

\subsection{Mathematical model}

Künzel's mathematical model of heat and moisture transport [8] was used in the simulations which can be formulated as

$$
\begin{gathered}
\frac{d \rho_{v}}{d \phi} \frac{\partial \phi}{\partial t}=\operatorname{div}\left[D_{\phi} \operatorname{grad} \phi+\delta_{p} \operatorname{grad}\left(\phi p_{s}\right)\right] \\
\frac{d H}{d T} \frac{\partial T}{\partial t}=\operatorname{div}(\lambda \operatorname{grad} T)+L_{v} \operatorname{div}\left[\delta_{p} \operatorname{grad}\left(\phi p_{s}\right)\right]
\end{gathered}
$$

where $\rho_{v}$ is the partial density of moisture, $\varphi$ relative humidity, $\delta_{p}$ permeability of water vapour, $p_{s}$ partial pressure of saturated water vapour, $H$ enthalpy density, $L_{v}$ heat of evaporation of water, $\lambda$ thermal conductivity and $T$ temperature,

$$
D_{\phi}=D_{w} \frac{d \rho_{v}}{d \phi}
$$

is liquid moisture diffusivity coefficient, $D_{w}$ capillary transport coefficient.

\subsection{Scheme of the construction detail}

Three variations of building envelopes based on zeolite concrete were chosen for the simulations in this paper. Initially, a zeolite concrete building envelope in a 
thickness of $500 \mathrm{~mm}$ without surface layers was analyzed. The second building envelope consisted of zeolite concrete provided with thermal insulating plaster $(10 \mathrm{~mm})$ from both sides. The third variation of building envelope was made of zeolite concrete $(500 \mathrm{~mm})$ with expanded polystyrene $(100 \mathrm{~mm})$ and thermal insulating plaster $(10 \mathrm{~mm})$. In this case, there was also $10 \mathrm{~mm}$ thick adhesive layer between concrete and thermal insulation. The scheme of all investigated variations of building envelope is captured in Figure 1.
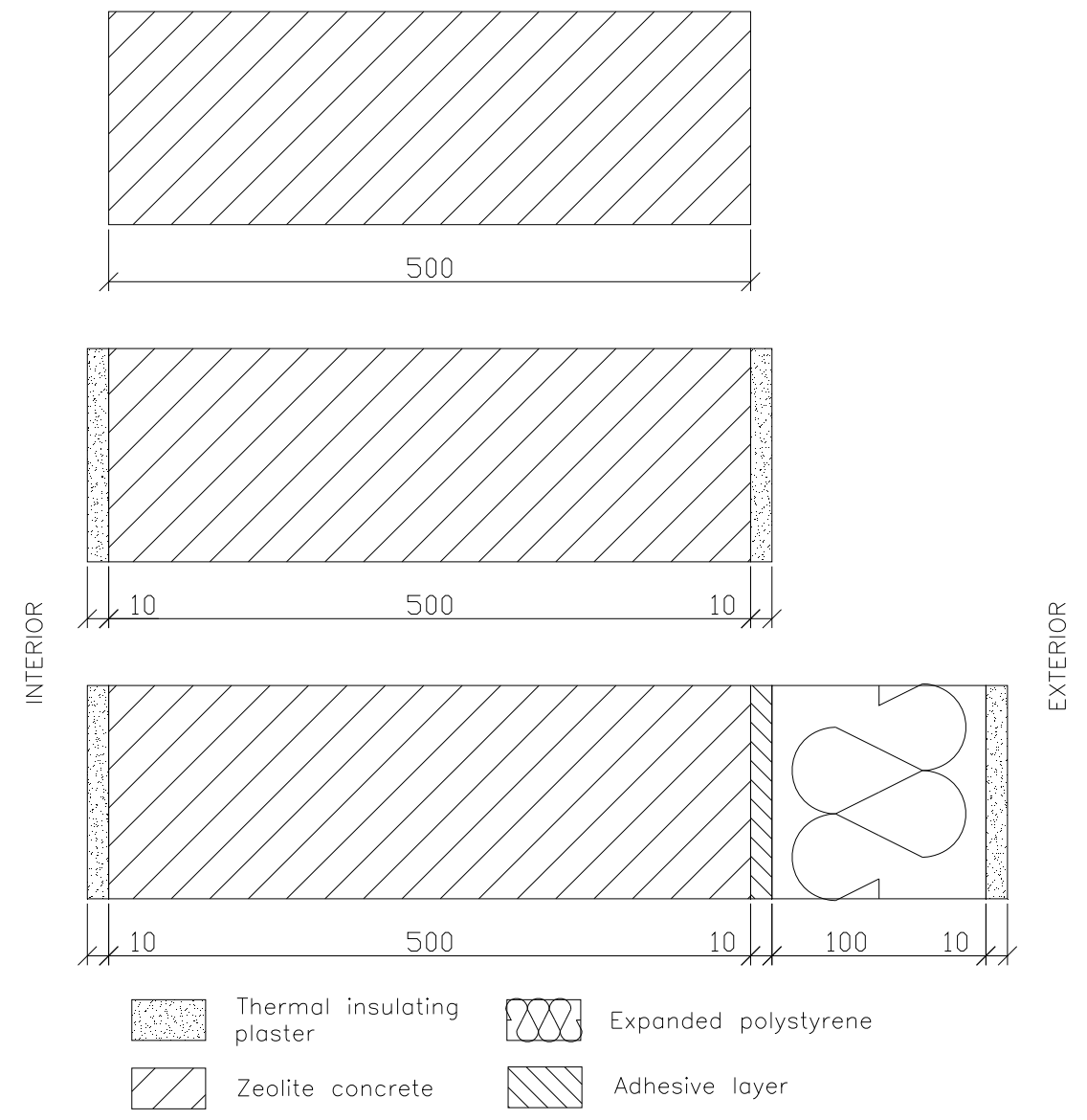

Figure 1: Scheme of analyzed construction details.

\subsection{Material parameters}

Basic physical, thermal and hygric properties of involved materials are summarized in Tables 3 and 4. The following symbols are used: $\rho$ - bulk density $\left[\mathrm{kg} / \mathrm{m}^{3}\right], \rho_{\text {mat }}-$ matrix density $\left[\mathrm{kg} / \mathrm{m}^{3}\right], \psi$-porosity $[\%], c-$ specific heat capacity $[\mathrm{J} / \mathrm{kgK}], \mu-$ water vapour diffusion resistance factor $[-], w-$ moisture 
content by volume $\left[\mathrm{m}^{3} / \mathrm{m}^{3}\right], \lambda-$ thermal conductivity $[\mathrm{W} / \mathrm{mK}], \kappa_{a p p}-$ apparent moisture diffusivity $\left[\mathrm{m}^{2} / \mathrm{s}\right]$. The data were taken mostly from Refs. [5] and [9] describing the measurements performed during the last few years in the laboratories of transport processes of Department of Materials Engineering and Chemistry, Faculty of Civil Engineering, Czech Technical University in Prague. The parameters of thermal insulating plaster were measured according to the methodology described in [10], but have not been published yet.

Table 3: Material parameters of zeolite concretes.

\begin{tabular}{|l|c|c|c|c|}
\hline Parameter & ZC-ref & ZC-10 & ZC-20 & ZC-40 \\
\hline$\rho\left[\mathrm{kg} / \mathrm{m}^{3}\right]$ & 2244 & 2194 & 2132 & 2036 \\
\hline$\psi[\%]$ & 13.4 & 15.7 & 18.0 & 22.4 \\
\hline$c[\mathrm{~J} /(\mathrm{kg} \mathrm{K})]$ & $738-923$ & $706-925$ & $729-980$ & $706-967$ \\
\hline$\mu[-]$ & $89.8-106.7$ & $68.9-81.9$ & $49.5-58.8$ & $29.8-35.4$ \\
\hline$\lambda_{\text {drv }}[\mathrm{W} /(\mathrm{m} \mathrm{K})]$ & 1.623 & 1.513 & 1.397 & 1.167 \\
\hline$\lambda_{\text {sat }}[\mathrm{W} /(\mathrm{m} \mathrm{K})]$ & 2.367 & 2.207 & 2.107 & 1.880 \\
\hline$\kappa_{\text {app }}\left[\mathrm{m}^{2} / \mathrm{s}\right]$ & $5.875 \mathrm{e}-9$ & $5.321 \mathrm{e}-9$ & $8.043 \mathrm{e}-9$ & $2.424 \mathrm{e}-8$ \\
\hline$w_{\text {hyg }}\left[\mathrm{m}^{3} / \mathrm{m}^{3}\right]$ & 0.090 & 0.112 & 0.115 & 0.132 \\
\hline
\end{tabular}

Table 4: Material parameters of other materials.

\begin{tabular}{|l|c|c|c|}
\hline Parameter & Adhesive layer & $\begin{array}{c}\text { Expanded } \\
\text { polystyrene }\end{array}$ & $\begin{array}{c}\text { Thermal insulating } \\
\text { plaster }\end{array}$ \\
\hline$\rho\left[\mathrm{kg} / \mathrm{m}^{3}\right]$ & 1430 & 16.5 & 434 \\
\hline$\psi[\%]$ & 42.6 & 0.065 & 40.7 \\
\hline$c[\mathrm{~J} /(\mathrm{kg} \mathrm{K})]$ & 1020 & 1570 & $646-1703$ \\
\hline$\mu[-]$ & 12.4 & $29-58$ & $3.1-13.9$ \\
\hline$\lambda_{d r v}[\mathrm{~W} /(\mathrm{m} \mathrm{K})]$ & 0.481 & 0.037 & 0.097 \\
\hline$\lambda_{\text {sat }}[\mathrm{W} /(\mathrm{m} \mathrm{K})]$ & 2.022 & 0.051 & 0.198 \\
\hline$\kappa_{a p p}\left[\mathrm{~m}^{2} / \mathrm{s}\right]$ & $1.070 \mathrm{e}-9$ & $1.5 \mathrm{e}-9$ & $1.28 \mathrm{e}-9$ \\
\hline$w_{h v g}\left[\mathrm{~m}^{3} / \mathrm{m}^{3}\right]$ & 0.0201 & 0.000178 & 0.020 \\
\hline
\end{tabular}

\subsection{Boundary conditions and time interval of simulation}

Dynamic climatic data in the form of Test Reference Year (TRY) for Prague were applied on the exterior side of building envelope. TRY contains long-term average hourly values of temperature, relative humidity, wind velocity and direction, rainfalls and several kinds of sun radiation. On the interior side constant values of relative humidity $55 \%$ and temperature $21^{\circ} \mathrm{C}$ were used. These data are prescribed in CSN 73 0540-2:2011 Thermal protection of buildings - Part 2: Requirements [11]. The simulation took 5 years in order to 
reach a dynamic steady state. All the presented results are related to the fifth year of simulation. Scheme of the applied boundary conditions is shown in Figure 2.

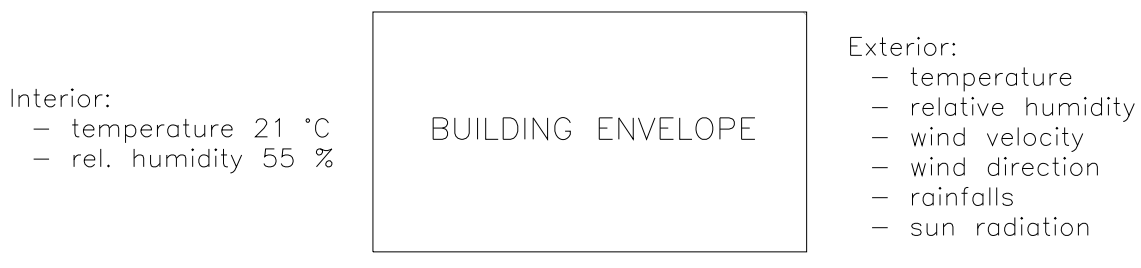

Figure 2: Scheme of applied boundary conditions.

\section{Computational results and discussion}

Service life of building materials is affected by many factors. Therefore, it is necessary to involve them as much as possible in order to obtain the most precise results of a service life analysis. However, current mathematical models for service life estimation of building envelopes allow assuming only several coupled phenomena, so it is necessary to focus only at the most important ones. In case of zeolite concrete we will assume that heat and moisture transport will be the crucial factor determining its service life. Because of high values of hygroscopic moisture content of zeolite concretes, exposing them to effects of weather conditions (see Tab. 3) may lead to liquid water appearance and freezing during a reference year which goes along with phase changes and volume expansion. This can finally cause mechanical damage of concrete and thus a subsequent decrease of service life of building envelope. Therefore, moisture and temperature fields across the envelope were simulated and critical moments were identified. As most critical factor, the occurrence of liquid moisture and temperature below zero at the same time in one point was assumed.

Computational simulations have shown that the composition of building envelope with external thermal insulation did not provide any conditions for creation of freeze/thaw cycles, because temperature in concrete was kept above zero and moreover, expanded polystyrene thanks to its low moisture diffusivity and high water vapor diffusion resistance factor protected the concrete against increased moisture ingress. Therefore, regardless of the type of zeolite concrete, its service life was not limited in this way. Because all the variations provided almost identical results, only selected figures are presented. Relative humidity profile of ZC-10 in summer (July $15^{\text {th }}$ ) is captured in Figure 3 and temperature profile of ZC-20 in winter (January $15^{\text {th }}$ ) is shown in Figure 4. In these figures, position $0 \mathrm{~mm}$ denotes the interior side. There are also gray vertical lines showing the interfaces between the particular materials. The temperature and relative humidity of ZC-40 (in concrete, $2 \mathrm{~mm}$ from interface with adhesive layer) as functions of time are depicted in Figure 5. 


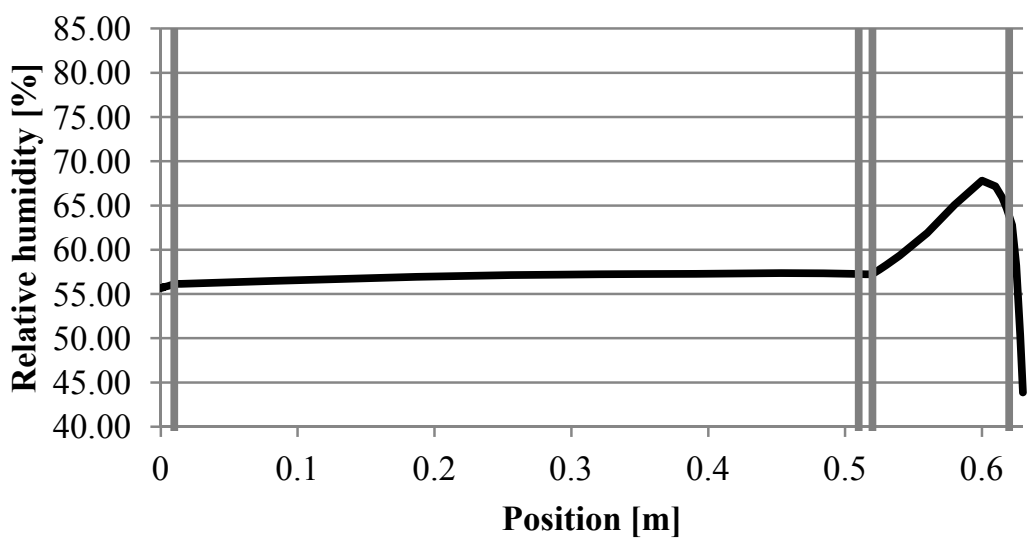

Figure 3: Relative humidity profile, ZC-10, summer period.

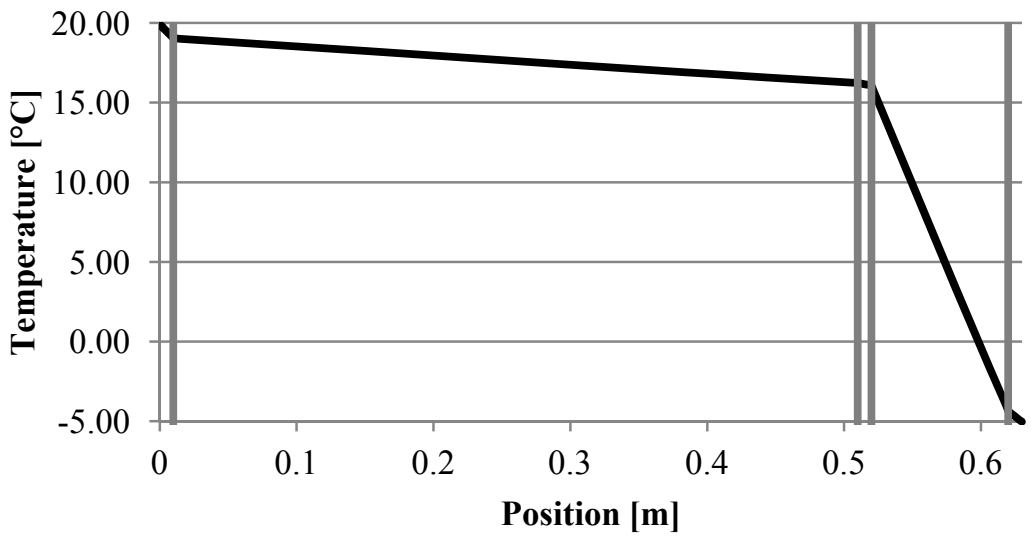

Figure 4: Temperature profile, ZC-20, winter period.

It is obvious that due to the presence of thermal insulation the relative humidity of concrete was permanently kept around $60 \%$ which was deeply under the hygroscopic threshold. The temperature ranged between 17 and $21^{\circ} \mathrm{C}$ during the reference year. Therefore, there were not any signs of potential creation of freeze/thaw cycles (see Fig. 5).

In a comparison to the composition with thermal insulation, zeolite concretes without surface layers provided much worse results. The differences were caused by the type of concrete and its hygric properties in particular. While the reference concrete was exposed to six freeze/thaw cycles per reference year due to the effects of weather conditions, zeolite admixtures could either decrease or increase this number. The worst results were obtained when ZC-40 concrete was used. Among all the types of concrete, this one had the highest moisture 

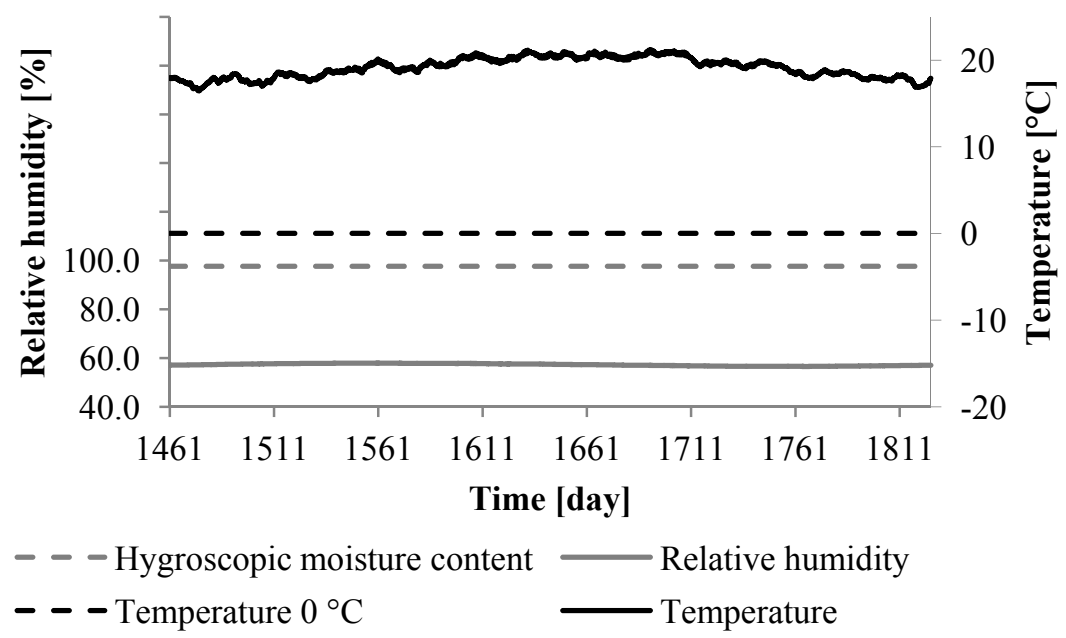

Figure 5: Temperature and relative humidity vs. time functions, ZC-40.

diffusivity and hygroscopic moisture content (see Tab. 3). Therefore, it was the most predisposed to the liquid moisture intake, which subsequently increased the risk of creation of freeze/thaw cycles. In this case we found seven cycles per a reference year.

However, it could not be stated generally that the lowest moisture diffusivity or hygroscopic moisture content provided the best results: they were obtained ( 5 cycles per reference year) when ZC-20 concrete was applied, with the values of moisture diffusivity and hygroscopic moisture content lying in the middle of the analyzed range. Thus, it could be assumed that there was an optimal set of values of hygric parameters which varied depending on the specific conditions. In this paper, as optimal seemed to be the properties of ZC-20 concrete, because ZC-10 provided conditions for creation of 6 cycles and as it was mentioned before, ZC40 gave 7 cycles per a reference year. A comparison of relative humidity profiles in summer day (July $15^{\text {th }}$ ) is shown in Figure 6. In this graph, only ZC-40 concrete differed significantly from the other types of envelope, which was caused by its high values of moisture diffusivity and hygroscopic moisture content allowing it a relatively fast response to the changes of weather (rain, relative humidity, etc.), while the other types of concretes reacted more slowly.

Temperature and relative humidity vs. time function of $\mathrm{ZC}-20$ concrete is captured in Figure 7.

Remarkable results were obtained, when zeolite concretes were provided with the exterior and interior plasters only. While other building materials such as aerated autoclaved concrete did evince certain number of freezing cycles in and even under the plaster [12], zeolite concretes did not. It could be caused, to a certain extent, by the parameters of the exterior plaster, but also by the 


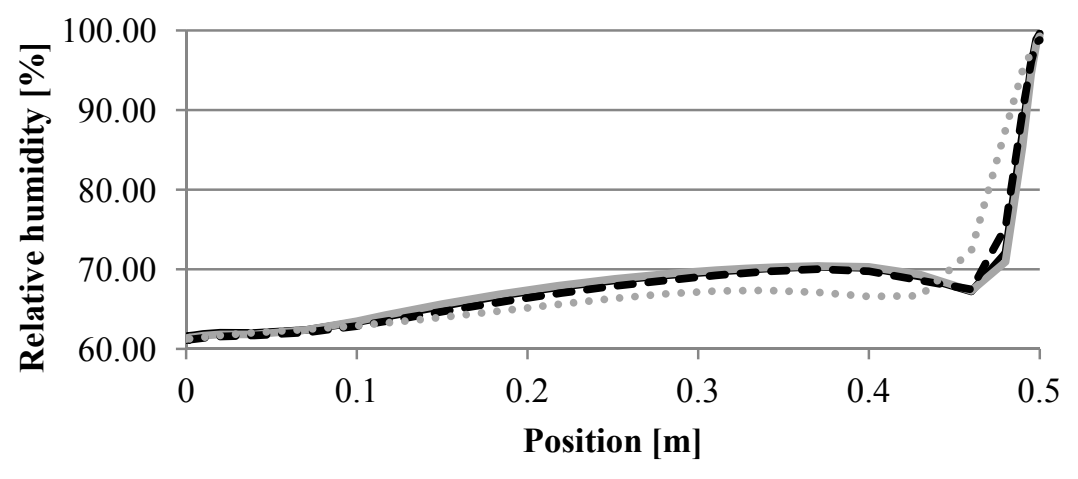

$\longrightarrow$ ZC-ref $\longrightarrow$ ZC-10 — ZC-20 $\cdots$ ZC-40

Figure 6: Relative humidity profiles, uncoated building envelope, summer period.

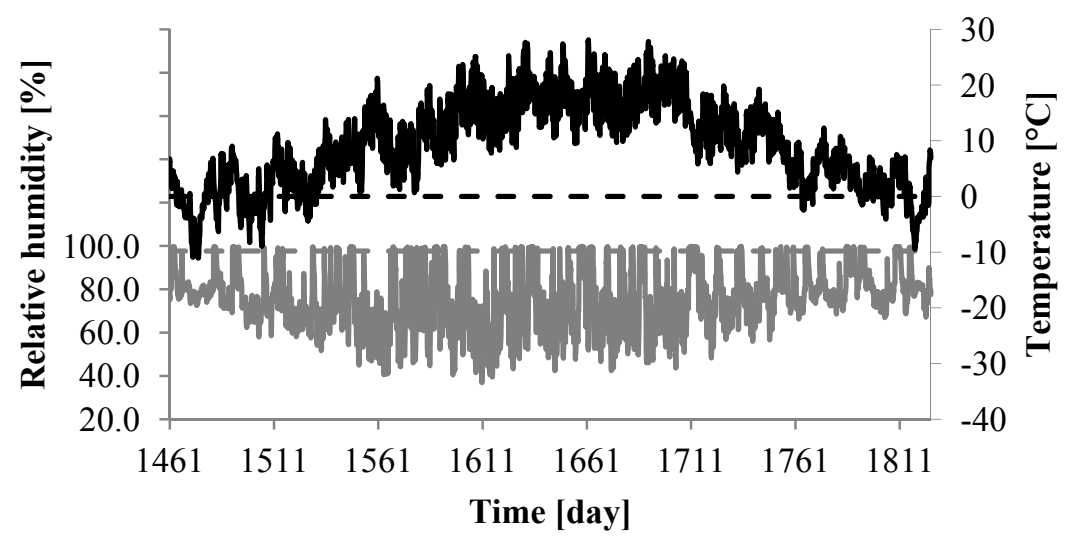

--- Hygroscopic moisture content $\longrightarrow$ Relative humidity

- - - Temperature $0{ }^{\circ} \mathrm{C} \quad-$ Temperature

Figure 7: Temperature and relative humidity vs. time function, ZC-20.

convenient hygric properties of zeolite concretes. Due to the relatively high value of moisture diffusivity, incidental liquid water could be quickly transported from the surface layers deeper to the envelope which led to its spreading and therefore decreasing of moisture content in the critical zone under the external surface of the building envelope. As well as concretes, also external plasters were not exposed to increased hygrothermal straining and there was not any freeze/thaw cycle appearing in the plaster during a reference year. Liquid water appeared in the plaster only shortly due to effects of rain, but it was quickly transported 
away. In this case it could be generally stated that the higher was the moisture diffusivity and hygroscopic moisture content of zeolite concretes, the lower was the risk of appearance of freeze/thaw cycles in the plaster. A comparison of relative humidity profiles of all variations of building envelope is shown in Fig. 8.

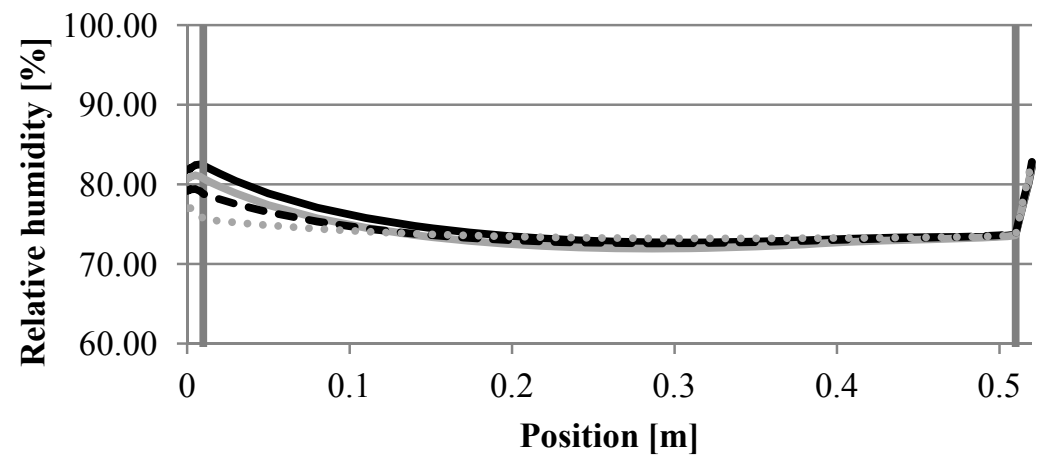

$\longrightarrow$ ZC-ref $\longrightarrow$ ZC-10 —- ZC-20 $\cdots \cdots$ ZC-40

Figure 8: Relative humidity profiles, building envelope with exterior and interior plaster, winter period.

The most principal results of the hygrothermal simulations for all investigated variations of building envelope are summarized in Table 5. The number in brackets denote the number of freeze/thaw cycles which were counted in the external plaster.

Table 5: Freeze/thaw cycles summary.

\begin{tabular}{|l|c|c|c|c|}
\hline & ZC-ref & ZC-10 & ZC-20 & ZC-40 \\
\hline No of surface layers & 6 & 6 & 5 & 7 \\
\hline Plaster & $0(0)$ & $0(0)$ & $0(0)$ & $0(0)$ \\
\hline EPS + plaster & $0(22)$ & $0(22)$ & $0(20)$ & $0(19)$ \\
\hline
\end{tabular}

\section{Conclusions}

The service life of a reference concrete and three concretes with zeolite admixture was analyzed from the point of view of freeze/thaw resistance. The results were obtained on the basis of the knowledge hygric and thermal fields which were calculated using numerical simulation of coupled heat and moisture transport.

According to the results presented in this paper, concrete without any surface layers was predisposed to the creation of up to 7 freeze/thaw cycles per a reference year, depending on the type of concrete. It was found that the optimal composition of zeolite concrete was not obvious. It depended on many factors, 
such as the climatic conditions, material thickness, etc. The best way how to find it was to use the results of numerical simulation of coupled heat and moisture transport using realistic weather data which could provide precise information in advance. Under Central European climatic conditions (Prague), the optimal amount of zeolite admixture was about $20 \%$ of cement mass because ZC-20 concrete gave the best results (only 5 freeze/thaw cycles). A higher content of zeolite admixture in concrete composition led to a worsening of freeze/thaw resistance, thus lower service life.

The service life of zeolite concrete structures could be easily extended by an application of thermal insulating plaster or thermal insulation materials. Both variations substantially reduced the presence of liquid moisture in concrete which is one of the essential conditions for creation of freeze thaw cycles.

In a comparison with some other building materials [12], zeolite concretes were more considerate to the applied external plasters. The service life of zeolite concrete with thermal insulating plaster was not limited by the effects of freeze/thaw cycles.

\section{Acknowledgement}

This research has been supported by the Czech Science Foundation, under project No P104/12/0308.

\section{References}

[1] Papadakis, V.G., \& Tsimas, S., Supplementary cementing materials in concrete: Part I: efficiency and design. Cement and Concrete Research, 37(6), pp. 877-885, 2007.

[2] Antiohos, S.K., Papageorgiou, A., Papadakis, V.G. \& Tsimas, S., Influence of quicklime addition on the mechanical properties and hydration degree of blended cements containing different fly ashes. Construction and Building Materials, 22(6), pp. 1191-1200, 2008.

[3] Federico, L.M., Chidiac, S.E., Waste glass as a supplementary cementitious material in concrete - Critical review of treatment methods. Cement and Concrete Composites, 31(8), pp. 606-610, 2009.

[4] Ganesan, K., Rajagopal, K. \& Thangavel, K., Evaluation of bagasse ash as supplementary cementitious material. Cement and Concrete Composites, 29(6), pp. 515-524, 2007.

[5] Vejmelková, E., Keppert, M., Ondráček, M. \& Černý, R., Effect of natural zeolite on the properties of high performance concrete. Cement Wapno Beton, 18(3), pp. 150-159, 2013.

[6] Černý, R., (ed). Complex System of Methods for Directed Design and Assessment of Functional Properties of Building Materials: Assessment and Synthesis of Analytical Data and Construction of the System, CTU Prague: Prague, 2010. 
[7] Kruis, J., Koudelka, T. \& Krejčí, T., Efficient computer implementation of coupled hydro-thermo-mechanical analysis. Mathematics and Computers in Simulation, 80, pp. 1578-1588, 2010.

[8] Künzel, H.M. Simultaneous Heat and Moisture Transport in Building Components, Ph. D. Thesis, IRB Verlag: Stuttgart, 1995.

[9] Jerman, M. \& Černý, R., Effect of moisture content on heat and moisture transport and storage properties of thermal insulation materials. Energy and Buildings, 53, pp. 39-46, 2012.

[10] Černý, R., (ed). Complex System of Methods for Directed Design and Assessment of Functional Properties of Building Materials and Its Application, CTU Prague: Prague, 2013.

[11] CSN 73 0540-2 Thermal Protection of Buildings - Part 2: Requirements, Czech Office for Standards, Metrology and Testing, Prague, 2011.

[12] Kočí, V., Maděra, J. \& Černý, R., Exterior thermal insulation systems for AAC building envelopes: Computational analysis aimed at increasing service life. Energy and Buildings, 47, pp. 84-90, 2012. 